\title{
Intranasal Insulin Improves Memory in Humans: Superiority of Insulin Aspart
}

\author{
Christian Benedict*,', Manfred Hallschmid', Katrin Schmitz', Bernd Schultes ${ }^{2}$, Frank Ratter ${ }^{3}$, \\ Horst L Fehm ${ }^{4}$, Jan Born' and Werner Kern ${ }^{4}$ \\ 'Department of Neuroendocrinology, University of Lübeck, Lübeck, Germany; ${ }^{2}$ Obesity Centre, Spitalregion St Gallen-Rorschach, Switzerland; \\ ${ }^{3}$ Novo Nordisk Germany, Mainz, Germany; ${ }^{4}$ Department of Internal Medicine I, University of Lübeck, Lübeck, Germany
}

\begin{abstract}
There is compelling evidence that intranasal administration of regular human insulin $(\mathrm{RH}-\mathrm{I})$ improves memory in humans. Owing to the reduced tendency of its molecules to form hexamers, the rapid-acting insulin analog insulin aspart (ASP-I) is more rapidly absorbed than $\mathrm{RH}-\mathrm{I}$ after subcutaneous administration. Since after intranasal insulin administration, ASP-I may also be expected to access the brain, we examined whether intranasal ASP-I has stronger beneficial effects on declarative memory than RH-I in humans. Acute (40 IU) and longterm ( $4 \times 40 \mathrm{IU} /$ day over 8 weeks) effects of intranasally administered ASP-I, RH-I, and placebo on declarative memory (word lists) were assessed in 36 healthy men in a between-subject design. Plasma insulin and glucose levels were not affected. After 8 weeks of treatment, however, word list recall was improved compared to placebo in both the ASP-I $(p<0.0 \mathrm{I})$ and the RH-I groups $(p<0.05)$. ASP-I-treated subjects performed even better than those of the $\mathrm{RH}-$-l-treated group $(p<0.05)$. Our results indicate that insulin-induced memory improvement can be enhanced by using ASP-I. This finding may be especially relevant for a potential clinical administration of intranasal insulin in the treatment of memory disorders like Alzheimer's disease.

Neuropsychopharmacology (2007) 32, 239-243. doi:I0. I038/sj.npp. I 30I 193; published online I6 August 2006
\end{abstract}

Keywords: intranasal administration; insulin aspart; regular human insulin; declarative memory

\section{INTRODUCTION}

The hippocampus and connected limbic brain structures are essential for the conscious retention and recollection of facts and events, that is, for the formation of declarative memory (Squire and Zola, 1996; Eichenbaum, 1999, 2004). These brain regions display a high density of insulin receptors (Baskin et al, 1994; Wickelgren, 1998), implicating that central nervous insulin signaling is involved in declarative memory processing. This assumption is supported by studies in animals as well as in humans. In rats, insulin receptor expression and phosphorylation in the hippocampus are upregulated after water maze training (Zhao et al, 1999). In humans, euglycemic intravenous infusions of insulin enhance both recall of previously learned words (Kern et al, 2001; Craft et al, 2003) and neuronal activity within the medio-temporal lobe (Rotte et al, 2005). However, owing to the strong systemic effects of

\footnotetext{
*Correspondence: Dr C Benedict, Department of Neuroendocrinology, University Schleswig-Holstein, Campus Lübeck, Ratzeburger Allee 160, Haus 23a, Lübeck 23538, Germany, Tel: + 49 45I 500 4602, Fax: + 49 45I 500 3640, E-mail: benedict@kfg.uni-luebeck.de

Received 9 February 2006; revised I 3 July 2006; accepted 17 July 2006 Online publication: 20 July 2006 at http://www.acnp.org/citations/ Npp072006060084/default.pdf
}

intravenous insulin administration, this method does not permit assessing long-term effects of insulin on memory. Intranasal administration of bioactive compounds has been demonstrated to effectively deliver drugs to the brain without inducing systemic side effects (Born et al, 2002; Ross et al, 2004; Thorne et al, 2004; for review see Illum, 2000). Recent studies have revealed beneficial effects of acute and long-term (8 weeks) intranasal administration of regular human insulin (RH-I) on declarative memory in humans (Benedict et al, 2004; Reger et al, 2006). As RH-I molecules tend to self-associate into dimeric, tetrameric, and hexameric units, their absorption after subcutaneous administration is delayed (Kang et al, 1991). In the insulin analog insulin aspart (ASP-I), the amino-acid proline in position B28 is replaced by aspartic acid, reducing the tendency of the insulin molecule to self-associate (Brange et al, 1990; Brange and Volund, 1999), whereas the binding profile to the insulin receptor is the same as of RH-I (Kurtzhals et al, 2000). Clinical studies have shown that after subcutaneous administration, ASP-I induces a faster onset of the hypoglycemic effect than RH-I owing to its faster reabsorption from the tissue into the blood (Gammeltoft et al, 1999). As the pharmacokinetic difference between ASP-I and RH-I may affect their ability to enter the brain and to induce central nervous system effects after 
intranasal administration, we examined whether ASP-I may improve declarative memory function in humans better than RH-I.

\section{MATERIALS AND METHODS}

36 men (age $18-35$ years, body mass index, BMI $<25 \mathrm{~kg} / \mathrm{m}^{2}$ ) without personal or family history of diabetes were examined in a double-blind, between-subject comparison. Subjects underwent a physical examination to ensure they were healthy. Ten hours before testing they had to fast and to abstain from coffee and alcoholic beverages. The study was approved by the local Ethics Committee on Research Involving Human Subjects, and written informed consent was obtained from all subjects.

Subjects were randomly assigned to three groups (each 12 men), which were adjusted for age (RH-I: $24.92 \pm 1.63$ years, ASP-I: $24.42 \pm 1.33$ years, placebo: $26.25 \pm 1.66$ years) and BMI (RH-I: $22.60 \pm 0.60 \mathrm{~kg} / \mathrm{m}^{2}$, ASP-I: $22.98 \pm 0.59 \mathrm{~kg} / \mathrm{m}^{2}$, placebo: $23.24 \pm 0.43 \mathrm{~kg} / \mathrm{m}^{2}$ ). The data of the RH-I and placebo conditions were partly derived from a male subsample of eight subjects per group from a previously published study (Benedict et al, 2004). Both groups $(n=12)$ were each supplemented by four subjects to match all groups according to age and BMI. During a 2-week baseline phase, all subjects received placebo. During the following 8-week treatment period, subjects were intranasally administered RH-I (Insulin Actrapid ${ }^{\circledR}$ HM, Novo Nordisk, Mainz, Germany), ASP-I (Insulin NovoLog ${ }^{\mathbb{R}}$ HM, Novo Nordisk, Mainz, Germany), or placebo (HOE 31 dilution buffer for H-Insulin, Aventis Pharma, Bad Soden, Germany) in the morning, around noon, in the evening, and before going to bed. Each dose consisted of either $0.4 \mathrm{ml}$ ASP-I or RH-I (each containing $40 \mathrm{IU}$, respectively) or vehicle administered within four puffs of $0.1 \mathrm{ml}$ (two per nostril), amounting to $1.6 \mathrm{ml}$ (160 IU) insulin or vehicle per day. Based on previous experiments (Born et al, 2002), a single dose of $40 \mathrm{IU}$ insulin was expected to induce temporary increases in cerebrospinal fluid concentrations of insulin distinctly above the normal level in healthy individuals. Sprays were stored in a refrigerator at $\sim 4^{\circ} \mathrm{C}$ and were replaced by new substance every 7 days. In order to assure compliance, subjects kept a protocol on their intake routine.

Declarative memory testing relied on the oral presentation of standardized lists of 30 nouns at a rate of $1 \mathrm{word} / \mathrm{s}$ (Fruehwald-Schultes et al, 2000; Kern et al, 2001). After a break of $3 \mathrm{~min}$, subjects wrote down within $90 \mathrm{~s}$ all words they still remembered. In the delayed recall sessions, that is, 1 week later, subjects again had to write down all words they memorized from this list. The number of correctly recalled words and the number of words falsely remembered from previously presented lists were registered. Experimental sessions were scheduled at 0800 hours and took place (A) at the beginning of the baseline phase, (B) at the beginning of the treatment Phase, and (C) 1 week before the end of the 8 -week treatment phase. Session A yielded baseline values of immediate memory recall. Session B allowed to assess the acute effects of ASP-I, RH-I, or placebo on immediate memory recall. The effects of a subchronic administration of insulin on immediate memory recall were examined in session C. Delayed memory recall was tested in separate

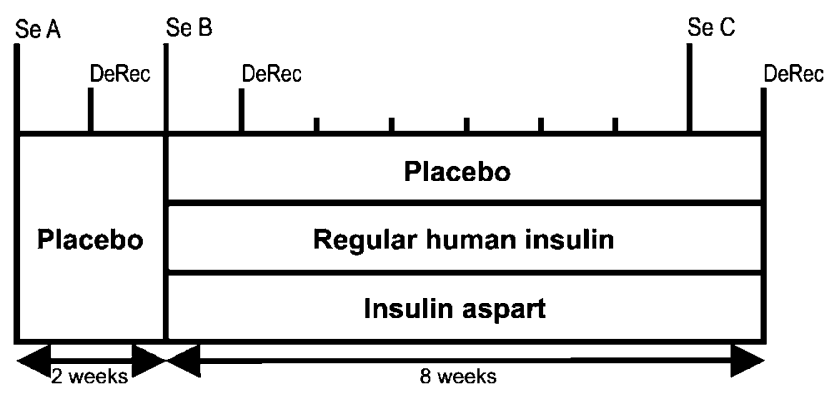

Figure I Time schedule. Three groups of 12 males each were intranasally treated with placebo for 2 weeks. Then, one group received $\mathrm{RH}-\mathrm{I}$, the second group received insulin aspart (ASP-I), and the third group continued with placebo. Intranasal treatments were performed four times per day ( $60 \mathrm{IU}$ insulin/day). Test session took place in the beginning of the study (session $A$, Se A), after the first intranasal administration of insulin (session B, Se B) and in the seventh week of the treatment period (session $\mathrm{C}$, Se $\mathrm{C}$ ). Delayed recall of words learned in each of these sessions was tested I week later (DeRec), respectively.

sessions taking place 1 week after the immediate sessions (see also Figure 1). All sessions were conducted $60 \mathrm{~min}$ after the administration of placebo, except for session (B) when initial doses of $40 \mathrm{IU}$ ASP-I, $40 \mathrm{IU}$ RH-I, or placebo were given $60 \mathrm{~min}$ before testing in order to examine acute effects of insulin. At the end of sessions A and B and at the end of the treatment period (ie, 1 week after session C), blood samples were collected for the determination of serum insulin (Pharmacia Insulin RIA100, Pharmacia \& Upjohn Inc., Uppsala, Sweden) and of plasma glucose (by the hexokinase method; Abbott; Wiesbaden, Germany).

\section{Data Reduction and Analysis}

One subject of the RH-I group did not participate in the last delayed word recall testing due to illness and was excluded from analysis. For baseline adjustment, values of the baseline session were subtracted from treatment values for each individual. The differences of word list recall performances were subjected to ANOVA with the repeated measures factor time. After these global analyses had yielded significant treatment $\times$ time interaction effects, separate analyses for the acute and subchronic treatment effects on word list recall were performed with one-way ANOVA with the between-subject factor treatment condition. For hormonal parameters and plasma glucose, ANOVA with repeated measures (between-factor: treatment; within-factor: time) were calculated. Where appropriate, single time points were compared with $t$-tests for independent samples. A $p$-value $<0.05$ was considered significant. Degrees of freedom were adjusted using the Greenhouse-Geisser correction.

\section{RESULTS}

During the baseline period, immediate and delayed word list recall performances did not differ between conditions (ASP-I vs RH-I vs placebo, immediate: $11.25 \pm 0.93 v s$ $10.75 \pm 0.93$ vs $12.17 \pm 0.93, \mathrm{~F}(2,35)=0.60, p>0.55$; delayed: $5.83 \pm 1.01$ vs $6.75 \pm 1.01$ vs $8.33 \pm 1.01, \quad \mathrm{~F}(2,35)=1.57$, $p>0.22)$. The word list recall performance displayed a 

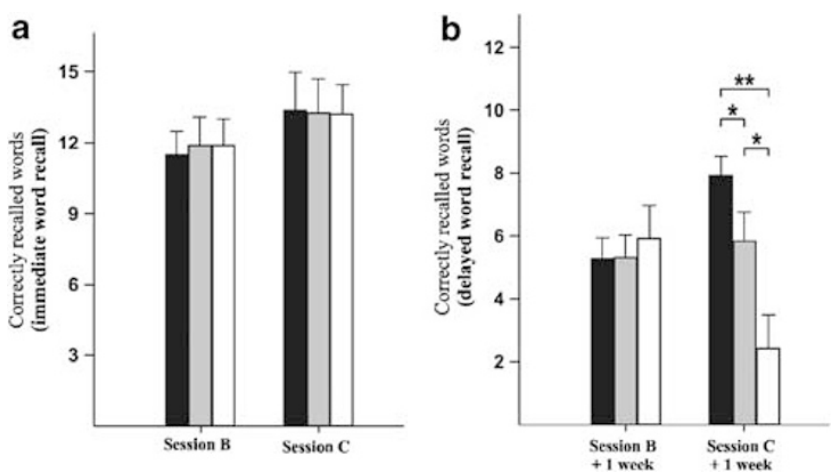

Figure 2 Acute and subchronic effects of intranasal insulin on (a) immediate and (b) delayed word recall. Word recall was tested 3 min after presenting a list of 30 words (immediate recall) and I week later (delayed recall). Words were presented $60 \mathrm{~min}$ after administering $40 \mathrm{l} \mathrm{U}$ of ASP-I (black), RH-I (gray), and placebo (white, session B), and $60 \mathrm{~min}$ after placebo administration following 7 weeks of ASP-I, RH-I (each $4 \times 40 \mathrm{lU} /$ day) or placebo (session $C$ ). Note that delayed recall testing did not assess acute treatment effects but those of I-week (acute) and 8-week (longterm) administration, respectively. Data were baseline-adjusted by subtracting values of the baseline session from treatment values. Significant differences between conditions are indicated (* $p<0.05$; $* * p<0.01$ ).

significant time $\times$ treatment interaction $(\mathrm{F}(2,32)=13.91$, $p<0.001)$. Post hoc analyses revealed that memory performance was significantly improved by insulin in the final delayed recall of words (ie, after 8 weeks of treatment; $\mathrm{F}(2,34)=10.12, p<0.001$ for ANOVA main effect; Figure 2). Although word recall after RH-I was significantly enhanced when compared to placebo $(\mathrm{F}(1,21)=1.18, p<0.03)$, ASP-I exerted an even stronger beneficial effect on delayed word recall $(\mathrm{F}(1,21)=0.33, p<0.05$ compared to $\mathrm{RH}-\mathrm{I}$; $\mathrm{F}(1,22)=3.81, p<0.001$ compared to placebo). Regarding the number of intrusions, that is, words remembered from other lists than the one presented before recall, no significant differences were found between conditions either in this session (ASP-I: $1.50 \pm 0.51$ words, RH-I: $1.27 \pm 0.41$ words, placebo: $1.67 \pm 0.57$ words; $\mathrm{F}(2,34)=0.15, p>0.86$ for main effect) or in the delayed recall following 1 week after acute administration of ASP-I, RH-I, and placebo (ASP-I: $1.42 \pm 0.45$ words, RH-I: $1.25 \pm 0.43$ words, placebo: $1.25 \pm 0.28$ words; $\mathrm{F}(2,35)=0.06, p>0.94$ for main effect). After acute insulin administration (session B), no effects on immediate $(\mathrm{F}(2,35)=0.81, p>0.92$ for main effect) and delayed recall of words, $\mathrm{F}(2,34)=0.25, p>0.78$ ) were found (Figure 2). Also, prolonged treatment with insulin compounds did not affect immediate recall of words measured in session $\mathrm{C}(\mathrm{F}(2,34)=0.01, p>0.92$ for main effect, Figure 2). Consistent with previous findings (Kern et al, 1999; Born et al, 2002) levels of plasma glucose and serum insulin were neither affected by acute nor by subchronic intranasal insulin administration (Table 1).

\section{DISCUSSION}

The present study compared the cognitive effects of intranasal administration of the insulin analog ASP-I with those of RH-I and of placebo. As reported previously (Benedict et al, 2004), 8 weeks of RH-I administration
Table I Plasma Glucose and Serum Insulin Levels after Acute and Long-Term Intranasal Insulin Administration

\begin{tabular}{lcccc}
\hline & ASP-I & RH-I & Placebo & \\
& Mean \pm SEM & Mean \pm SEM & Mean \pm SEM & P \\
\hline Plasma glucose (mmol/I) & & & & \\
Session A & $4.93 \pm 0.17$ & $4.80 \pm 0.13$ & $4.93 \pm 0.17$ & $0.7 \mid$ \\
Session B & $4.71 \pm 0.09$ & $4.73 \pm 0.03$ & $4.72 \pm 0.12$ & 0.43 \\
Session C+I week & $4.94 \pm 0.10$ & $4.81 \pm 0.09$ & $4.74 \pm 0.12$ & 0.98 \\
& & & & \\
Serum insulin ( $\mu / \mathrm{U} / \mathrm{ml})$ & & & & \\
Session A & $7.88 \pm 1.51$ & $5.56 \pm 0.69$ & $6.65 \pm 1.14$ & 0.38 \\
Session B & $5.35 \pm 0.72$ & $6.18 \pm 0.59$ & $7.32 \pm 1.43$ & 0.25 \\
Session C+I week & $6.13 \pm 1.25$ & $5.33 \pm 0.72$ & $6.49 \pm 0.88$ & 0.81 \\
\hline
\end{tabular}

Blood samples were taken (A) after the first intranasal administration of placebo, (B) after the first intranasal administration of insulin aspart (ASP-I, $40 \mathrm{IU}$ ), regular human insulin ( $\mathrm{RH}-\mathrm{I}, 40 \mathrm{IU})$, and placebo and at the end of the 8-week intranasal treatment period with ASP-I, RH-I (each $4 \times 40 \mathrm{IU} /$ day), and placebo (I week after session C). Data are means \pm SEM. For statistical analysis, values of the baseline session were individually subtracted from treatment values. Right column indicates $p$-values for main effects of one-way ANOVA. Note that data of the $\mathrm{RH}-\mathrm{I}$ and placebo conditions are from Benedict et al (2004).

significantly improved declarative memory performance as assessed by a delayed recall of words learned 1 week earlier. Eight weeks of ASP-I administration even exceeded this effect and yielded significantly improved delayed word recall both in comparison with the placebo condition and with RH-I. Our data indicate that the beneficial effect of intranasal insulin on memory can be enhanced by administering pharmacokinetically altered insulin analogs. On the background of increasing evidence that Alzheimer's disease (AD) is a neuroendocrine disorder with strikingly reduced CNS expression of genes encoding insulin, IGF-I and IGF-II, as well as the insulin and IGF-I receptors (Rivera et al, 2005), our finding of improved memory performance after intranasal intake of insulin and its analogs may be of significance for the treatment of memory impairments. This is supported by findings of facilitated recall of verbal memory after intravenous and intranasal treatment with insulin in memory-impaired adults (Craft et al, 1999; Reger et al, 2006).

Most recently, also acute effects of intranasal insulin on declarative memory have been reported, demonstrating that recall of previously learned words was enhanced after administration of up to $40 \mathrm{IU}$ of RH-I in patients suffering from AD (Reger et al, 2006). However, corresponding with our results, healthy control subjects of this study did not benefit from acute insulin treatment. Whereas $\mathrm{AD}$ patients might display a higher sensitivity to the cognitive effects of central nervous insulin owing to their lower CSF-to-plasma insulin ratio (Craft et al, 1996), our results show that neither a single dose of 40 IU of RH-I nor of ASP-I is potent enough to exhibit effects on declarative memory.

Regarding the delayed recall of words, the insulininduced improvement observed in our study occurred on the background of a generally decreasing performance $(\mathrm{F}(1,84)=11.09, p<0.02$ for overall ANOVA with withinfactor time). This decrease across sessions in correctly 
recalled words most probably was due to intrusions from previous word lists, that is, falsely recalled words learned before the presentation of the actual test list (Underwood, 1957; Postman, 1962). One or two intrusions per session registered in the present experiments show that proactive interferences occurred, but do not indicate their actual number because most of them may not have been consciously remembered by our subjects. As it is plausible that these factors had a comparable influence on both the treatment and the placebo groups, it seems justified to conclude that the superior memory performances of the treatment groups after 8 weeks of insulin indicate an improving influence of subchronic insulin on long-term memory. In this context, it is important to note that the 1 week delay between learning and recall was substantially longer than the delay of 20-30 min more frequently used in experimental memory assessments and that longer delays render memory consolidation per se more prone to interfering disturbances. Nevertheless, a 1 week interval between learning and recall is a valid means of assessing long-term memory formation (eg, Dudai, 2004).

It might be argued that differences in insulin sensitivity lead to the greater potential of ASP-I than RH-I to enhance declarative memory. Although no baseline insulin/glucose tolerance test was performed, measurements of basal homeostatic model assessment values, reflecting beta-cell function and insulin resistance (Wallace and Matthews, $2002)$, did not support this assumption $(p>0.43)$. The neuronal mechanisms underlying the improvement of declarative memory after intranasal insulin administration cannot be derived from our study. Central nervous system insulin is involved in a number of neuronal mechanisms assumed to constitute memory processing (for review, see Zhao et al, 2004). Previous studies have provided clear evidence that declarative memory formation depends on intact hippocampal functioning (Kessels et al, 2001; Bayley et al, 2005). Hippocampal and cortical insulin signaling pathways have been shown to play a pivotal role in enabling long-term memory consolidation by modulating neuronal activity and triggering mechanisms that are required for establishing synaptic plasticity (Gasparini and $\mathrm{Xu}, 2003$; Zhao et al, 2004; Craft and Watson, 2004; Wada et al, 2005). Thus, it is likely that after intranasal administration, insulin improves neuronal processes within these hippocampal and connected structures. Insulin may promote the expression of $N$-methyl-D-aspartate receptors (Skeberdis et al, 2001) and thus contribute to the formation of neuronal connections via synaptic long-term potentiation, a mechanism assumed to be essential for declarative memory formation (Castellano et al, 2001; Liu et al, 2004). The different pharmacokinetic properties of ASP-I in comparison to RH-I may add to the effects that insulin per se exerts on central nervous memory formation. In contrast to RH-I, that consists primarily of hexamers, ASP-I predominantly forms monomers so that after subcutaneous administration, it is more rapidly absorbed and lowers blood glucose more quickly than RH-I (Raslova et al, 2004; Hermansen et al, 2004). During intranasal administration, their reduced tendency to form hexamers may increase the number of ASP-I molecules transported from the nasal cavity to the brain and enhance insulin's effects on hippocampal memory processing.
In sum, our results demonstrate that after intranasal administration of identical doses, ASP-I has a distinctly greater potential than RH-I to improve memory in humans. Given that insulin and insulin-like factors not only protect brain tissue, but also favor processes such as neurogenesis and synaptogenesis (O'Kusky et al, 2000; van der Heide et al, 2005), and on the background of reduced CNS expression of genes encoding insulin and related messengers in patients suffering from $\mathrm{AD}$ (Steen et al, 2005), this outcome may be of considerable relevance for future clinical applications of insulin compounds in the treatment of memory disorders.

\section{ACKNOWLEDGEMENTS}

We thank Aero Pump GmbH, 65239 Hochheim, Germany, for generously providing us with precision nasal air pumps, and Novo Nordisk, 55127 Mainz, Germany, for providing us with regular human insulin and insulin aspart. We thank Anja Bublitz, Ingrid von Lützau, Christiane Otten, and Anja Otterbein for skilled technical assistance. This work was supported by the Deutsche Forschungsgemeinschaft, SFB 654/B3.

\section{REFERENCES}

Baskin DG, Schwartz MW, Sipols AJ, D’Alessio DA, Goldstein BJ, White MF (1994). Insulin receptor substrate-1 (IRS-1) expression in rat brain. Endocrinology 134: 1952-1955.

Bayley PJ, Gold JJ, Hopkins RO, Squire LR (2005). The neuroanatomy of remote memory. Neuron 46: 799-810.

Benedict C, Hallschmid M, Hatke A, Schultes B, Fehm HL, Born J et al (2004). Intranasal insulin improves memory in humans. Psychoneuroendocrinology 29: 1326-1334.

Born J, Lange T, Kern W, McGregor GP, Bickel U, Fehm HL (2002). Sniffing neuropeptides: a transnasal approach to the human brain. Nat Neurosci 5: 514-516.

Brange J, Owens DR, Kang S, Volund A (1990). Monomeric insulins and their experimental and clinical implications. Diabetes Care 13: 923-954.

Brange J, Volund A (1999). Insulin analogs with improved pharmacokinetic profiles. Adv Drug Deliv Rev 35: 307-335.

Castellano C, Cestari V, Ciamei A (2001). NMDA receptors and learning and memory processes. Curr Drug Targets 2: 273-283.

Craft S, Asthana S, Cook DG, Baker LD, Cherrier M, Purganan K et al (2003). Insulin dose-response effects on memory and plasma amyloid precursor protein in Alzheimer's disease: interactions with apolipoprotein E genotype. Psychoneuroendocrinology 28: 809-822.

Craft S, Asthana S, Newcomer JW, Wilkinson CW, Matos IT, Baker LD et al (1999). Enhancement of memory in Alzheimer disease with insulin and somatostatin, but not glucose. Arch Gen Psychiatry 56: 1135-1140.

Craft S, Newcomer J, Kanne S, gogo-Jack S, Cryer P, Sheline Y et al (1996). Memory improvement following induced hyperinsulinemia in Alzheimer's disease. Neurobiol Aging 17: 123-130.

Craft S, Watson GS (2004). Insulin and neurodegenerative disease: shared and specific mechanisms. Lancet Neurol 3: 169-178.

Dudai Y (2004). The neurobiology of consolidations, or, how stable is the engram? Annu Rev Psychol 55: 51-86.

Eichenbaum H (1999). The hippocampus and mechanisms of declarative memory. Behav Brain Res 103: 123-133.

Eichenbaum H (2004). Hippocampus: cognitive processes and neural representations that underlie declarative memory. Neuron 44: 109-120. 
Fruehwald-Schultes B, Born J, Kern W, Peters A, Fehm HL (2000). Adaptation of cognitive function to hypoglycemia in healthy men. Diabetes Care 23: 1059-1066.

Gammeltoft S, Hansen BF, Dideriksen L, Lindholm A, Schaffer L, Trub T et al (1999). Insulin aspart: a novel rapid-acting human insulin analogue. Expert Opin Investig Drugs 8: 1431-1442.

Gasparini L, Xu H (2003). Potential roles of insulin and IGF-1 in Alzheimer's disease. Trends Neurosci 26: 404-406.

Hermansen K, Fontaine P, Kukolja KK, Peterkova V, Leth G, Gall MA (2004). Insulin analogues (insulin detemir and insulin aspart) versus traditional human insulins (NPH insulin and regular human insulin) in basal-bolus therapy for patients with type 1 diabetes. Diabetologia 47: 622-629.

Illum L (2000). Transport of drugs from the nasal cavity to the central nervous system. Eur J Pharm Sci 11: 1-18.

Kang S, Creagh FM, Peters JR, Brange J, Volund A, Owens DR (1991). Comparison of subcutaneous soluble human insulin and insulin analogues (AspB9, GluB27; AspB10; AspB28) on mealrelated plasma glucose excursions in type I diabetic subjects. Diabetes Care 14: 571-577.

Kern W, Born J, Schreiber H, Fehm HL (1999). Central nervous system effects of intranasally administered insulin during euglycemia in men. Diabetes 48: 557-563.

Kern W, Peters A, Fruehwald-Schultes B, Deininger E, Born J, Fehm HL (2001). Improving influence of insulin on cognitive functions in humans. Neuroendocrinology 74: 270-280.

Kessels RP, de Haan EH, Kappelle LJ, Postma A (2001). Varieties of human spatial memory: a meta-analysis on the effects of hippocampal lesions. Brain Res Rev 35: 295-303.

Kurtzhals P, Schaffer L, Sorensen A, Kristensen C, Jonassen I, Schmid C et al (2000). Correlations of receptor binding and metabolic and mitogenic potencies of insulin analogs designed for clinical use. Diabetes 49: 999-1005.

Liu L, Wong TP, Pozza MF, Lingenhoehl K, Wang Y, Sheng M et al (2004). Role of NMDA receptor subtypes in governing the direction of hippocampal synaptic plasticity. Science 304: 1021-1024.

O’Kusky JR, Ye P, D’Ercole AJ (2000). Insulin-like growth factor-I promotes neurogenesis and synaptogenesis in the hippocampal dentate gyrus during postnatal development. J Neurosci 20: $8435-8442$.

Postman L (1962). The temporal course of proactive inhibition for serial lists. J Exp Psychol 63: 361-369.

Raslova K, Bogoev M, Raz I, Leth G, Gall MA, Hancu N (2004). Insulin detemir and insulin aspart: a promising basal-bolus regimen for type 2 diabetes. Diabetes Res Clin Pract 66: 193-201.

Reger MA, Watson GS, Frey WH, Baker LD, Cholerton B, Keeling ML et al (2006). Effects of intranasal insulin on cognition in memory-impaired older adults: modulation by APOE genotype. Neurobiol Aging 27: 451-458.
Rivera EJ, Goldin A, Fulmer N, Tavares R, Wands JR, de la Monte SM (2005). Insulin and insulin-like growth factor expression and function deteriorate with progression of Alzheimer's disease: link to brain reductions in acetylcholine. J Alzheimers Dis 8: 247-268.

Ross TM, Martinez PM, Renner JC, Thorne RG, Hanson LR, Frey WH (2004). Intranasal administration of interferon beta bypasses the blood-brain barrier to target the central nervous system and cervical lymph nodes: a non-invasive treatment strategy for multiple sclerosis. J Neuroimmunol 151: 66-77.

Rotte M, Baerecke C, Pottag G, Klose S, Kanneberg E, Heinze HJ et al (2005). Insulin affects the neuronal response in the medial temporal lobe in humans. Neuroendocrinology 81: 49-55.

Skeberdis VA, Lan J, Zheng X, Zukin RS, Bennett MV (2001). Insulin promotes rapid delivery of $N$-methyl-D-aspartate receptors to the cell surface by exocytosis. Proc Natl Acad Sci USA 98: 3561-3566.

Squire LR, Zola SM (1996). Structure and function of declarative and nondeclarative memory systems. Proc Natl Acad Sci USA 93: 13515-13522.

Steen E, Terry BM, Rivera EJ, Cannon JL, Neely TR, Tavares R et al (2005). Impaired insulin and insulin-like growth factor expression and signaling mechanisms in Alzheimer's disease-is this type 3 diabetes? J Alzheimers Dis 7: 63-80.

Thorne RG, Pronk GJ, Padmanabhan V, Frey WH (2004). Delivery of insulin-like growth factor-I to the rat brain and spinal cord along olfactory and trigeminal pathways following intranasal administration. Neuroscience 127: 481-496.

Underwood BJ (1957). Interference and forgetting. Psychol Rev 64: 49-60.

van der Heide LP, Kamal A, Artola A, Gispen WH, Ramakers GM (2005). Insulin modulates hippocampal activity-dependent synaptic plasticity in a $N$-methyl-D-aspartate receptor and phosphatidylinositol-3-kinase-dependent manner. J Neurochem 94: 1158-1166.

Wada A, Yokoo H, Yanagita T, Kobayashi H (2005). New twist on neuronal insulin receptor signaling in health, disease, and therapeutics. J Pharmacol Sci 99: 128-143.

Wallace TM, Matthews DR (2002). The assessment of insulin resistance in man. Diabetic Med 19: 527-534.

Wickelgren I (1998). Tracking insulin to the mind. Science 280: 517-519.

Zhao W, Chen H, Xu H, Moore E, Meiri N, Quon MJ et al (1999). Brain insulin receptors and spatial memory. Correlated changes in gene expression, tyrosine phosphorylation, and signaling molecules in the hippocampus of water maze trained rats. J Biol Chem 274: 34893-34902.

Zhao WQ, Chen H, Quon MJ, Alkon DL (2004). Insulin and the insulin receptor in experimental models of learning and memory. Eur J Pharmacol 490: 71-81. 